\title{
Substrate Stiffness Modulates Gene Expression and \\ Phenotype in Neonatal Cardiomyocytes In Vitro
}

\section{Forte, Giancarlo}

2012-09-06

Forte, G , Pagliari , S , Ebara , M , Uto , K , Van Tam , J K, Romanazzo , S , Escobedo-Lucea , C , Romano , E , Di Nardo , P , Traversa , E \& Aoyagi , T 2012 , ' Substrate Stiffness Modulates Gene Expression and Phenotype in Neonatal Cardiomyocytes In Vitro ' , Tissue Engineering. Part A. Tissue Engineering , vol. 18 , no. 17-18 , pp. 1837-1848 . https://doi.org/10.1089/ten.tea.2011.0707

http://hdl.handle.net/10138/41575

https://doi.org/10.1089/ten.tea.2011.0707

publishedVersion

Downloaded from Helda, University of Helsinki institutional repository.

This is an electronic reprint of the original article.

This reprint may differ from the original in pagination and typographic detail.

Please cite the original version. 


\title{
Substrate Stiffness Modulates Gene Expression and Phenotype in Neonatal Cardiomyocytes In Vitro
}

\author{
Giancarlo Forte, Ph.D., ${ }^{1, *}$ Stefania Pagliari, Ph.D., ${ }^{2,}{ }^{*}$ Mitsuhiro Ebara, Ph.D., ${ }^{1}$ Koichiro Uto, Ph.D., ${ }^{1}$ \\ Janice Kal Van Tam, Ph.D., Sara Romanazzo, M.S., ${ }^{2}$ Carmen Escobedo-Lucea, Ph.D., ${ }^{3-5}$ \\ Elena Romano, Ph.D., ${ }^{6}$ Paolo Di Nardo, M.D., ${ }^{7}$ Enrico Traversa, Ph.D., ${ }^{2}$ and Takao Aoyagi, Ph.D. ${ }^{1}$
}

Biomaterials to be used as cell delivery systems for cardiac tissue engineering should be able to comply with cardiac muscle contractile activity, while favoring cell survival and neo-angiogenesis in a hostile environment. Biocompatible synthetic materials can be tailored to mimic cardiac tissue three-dimensional organization in the micro- and nanoscales. Nonetheless, they usually display mechanical properties that are far from those of the native myocardium and thus could affect host cell survival and activity. In the present investigation, inert poly-६caprolactone planar layers were manufactured to change the surface stiffness (with Young's modulus ranging from 1 to $133 \mathrm{MPa}$ ) without changing matrix chemistry. These substrates were challenged with neonatal murine cardiomyocytes to study the possible effect of substrate stiffness on such cell behavior without changing biological cues. Interestingly, softer substrates $(0.91 \pm 0.08$ and $1.53 \pm 0.16 \mathrm{MPa})$ were found to harbor mostly mature cardiomyocytes having assembled sarcomeres, as shown by the expression of alpha actinin and myosin heavy chain in typical striations and the upregulation of sarcomeric actin mRNA. On the other hand, a preferential expression of immature cardiac cell genes (Nkx-2.5) and proteins (GATA-4) in cardiac cells grown onto stiffer materials $(49.67 \pm 2.56$ and $133.23 \pm 8.67 \mathrm{MPa})$ was detected. This result could not be ascribed to significant differences in cell adhesion or proliferation induced by the substrates, but to the stabilization of cardiomyocyte differentiated phenotype induced by softer layers. In fact, cardiac cell electromechanical coupling was shown to be more organized on softer surfaces, as highlighted by connexin 43 distribution. Moreover, a differential regulation of genes involved in extracellular matrix remodeling was detected on soft films $(0.91 \pm 0.08 \mathrm{MPa})$ as compared with the stiffest $(133.23 \pm 8.67 \mathrm{MPa})$. Finally, the upregulation of a number of genes involved in inflammatory processes was detected when the stiffest polymer is used. These events highlight the differences in cell mechanosensitivity in a heterogeneous cell preparation and are likely to contribute to the differences encountered in cardiac cell phenotype induced by substrate stiffness.

\section{Introduction}

$\mathbf{T}$ ISSUE ENGINEERING by means of biodegradable polymers is emerging as a challenging opportunity to treat cardiovascular diseases. The relationships between cells and scaffold chemical and mechanophysical properties are paramount for the definition of safe protocols to transfer tissue engineering techniques to the bedside. In fact, recent reports focused on the opportunity to tune the properties of synthetic substrates to better mimic the features of the tissue of interest, as to provide the cells to be implanted with tissuespecific cues. ${ }^{1,2}$ In this context, significant advancements have been recently achieved in the identification of substrate stiffness as one of the key factors in progenitor and stem cell fate determination. ${ }^{3-7}$ Moreover, changes in such a substrate property have been also shown to trigger biological

\footnotetext{
${ }^{1}$ Biomaterials Unit, International Center for Materials Nanoarchitectonics (MANA), National Institute for Materials Science (NIMS), Tsukuba, Japan.

${ }^{2}$ Sustainability Materials Unit, International Center for Materials Nanoarchitectonics (MANA), National Institute for Materials Science (NIMS), Tsukuba, Japan.

${ }^{3}$ Comparative Neurobiology Unit, Instituto Cavanilles, University of Valencia-RETICS, Valencia, Spain.

${ }^{4}$ Regenerative Medicine Program, Centro de Investigación Principe Felipe, Valencia, Spain.

${ }^{5}$ Division of Biopharmaceutics and Pharmacokinetics, Faculty of Pharmacy, University of Helsinki, Helsinki, Finland.

${ }^{6}$ Department of Biology, University of Rome "Tor Vergata," Rome, Italy.

${ }^{7}$ Laboratory of Cellular and Molecular Cardiology, Department of Internal Medicine, University of Rome "Tor Vergata," Rome, Italy.

*These two authors equally contributed to this work.
} 
responses in several differentiated cell types. ${ }^{8-10}$ The transduction of mechanical signals in differentiated as well in undifferentiated cells has been mainly ascribed to the activation of RhoA/ROCK signaling pathway. ${ }^{11-13}$ In human mesenchymal stem cells, these signals appear to be integrated by cytoskeleton tension ${ }^{14}$ and $\mathrm{Ca}^{2+}$ oscillations ${ }^{15}$ to foster stem cell determination.

The effects of substrate elasticity on cardiac cells have been addressed by few research groups so far. In embryonic cardiomyocytes, substrate stiffness was shown to affect contractility, with tissue-like Young's modulus appearing more suitable for beating activity; ${ }^{16}$ consistently, neonatal cardiac cell maturation was demonstrated to be impaired on stiff substrates, while the formation of functional striations in skeletal myotubes was found to be optimal on substrates having a tissue-like stiffness $(12 \mathrm{kPa}) .{ }^{17}$ Nonetheless, the process of cell fusion leading to the formation of myotubes did not seem to be affected by substrate mechanical properties. ${ }^{18}$ In vivo, the slight variations in substrate stiffness following scar formation after myocardial infarction ${ }^{19}$ have been proposed to impair injected or resident stem cell ability to be retained in and repair the injured myocardium, ${ }^{20-22}$ while marked differences in extracellular matrix rigidity are considered predictive of solid tumor malignancy or progression. ${ }^{23-25}$ The ability of living cells to activate specific signaling pathways in response to mechanical stimuli has been recently demonstrated to be highly cell specific, ${ }^{4,18,26}$ this evidence being likely to reflect differences in in vivo cell physiology. Given the ability of cells to sense the substrate they grow on and their acknowledged capacity to convert such "feelings" in a biological behavior, one cannot neglect the possibility that scaffolds developed for a specific in vivo application could interfere with host cell behavior once they are implanted. In the case of scaffolds to be used in cardiac tissue engineering, they should be able to comply with cardiac contractility, ${ }^{27}$ while also representing an easy tool to be handled by the surgeons. Although natural and synthetic hydrogels represent valuable candidates to mimic cardiac tissue microenvironment in terms of mechanophysical properties, ${ }^{28}$ the use of three-dimensional (3D) scaffolds allows the control of graft shape and size, as well as the possibility to use the correct number of cells. ${ }^{29-31}$ Nonetheless, the possibility that a foreign body reaction could be induced cannot be excluded when synthetic or animal-derived materials are used. ${ }^{32,33}$
A number of natural biomaterials have been so far proposed as scaffolds to treat cardiac pathologies, including alginate, fibrin, collagen, and chitosan. ${ }^{34-37}$ Also, synthetic derivatives of poly-lactic acid, poly-e-caprolactone (PCL), and blends obtained with glycolic acid (PLGA) have been investigated as cell delivery systems for future applications. As a bulk, such materials are known to be far stiffer than myocardium, while microfabrication techniques can be used to obtain an anisotropic distribution of their rigidity. $4,38,39$ Aim of the present work is to study the interaction between stiff substrates (from $0.91 \pm 0.08$ to $133.23 \pm 8.67 \mathrm{MPa}$ ) and neonatal cardiomyocytes. For this purpose, planar PCL layers displaying different overall stiffness values were obtained by cross-linking tetra-branched PCL with acrylate end-groups in the presence of linear PCL telechelic diacrylates, and tested for their ability to sustain murine neonatal cardiomyocyte adhesion and maturation. Because PCL is a semicrystalline polymer that has a melting temperature $\left(T_{m}\right)$ over which the mobility of polymer chains changes significantly, the cross-linked PCLs successfully offer branchstructure-dependent stiffness without changing the surface wettability. Our results show that softer materials (around $1 \mathrm{MPa}$ stiffness) favor the appearance of cells having correctly oriented sarcomere structure and electromechanical coupling, while the stiffer ones (in the high MPa range) enhance the number of GATA-4- and Nkx-2.5-expressing noncontractile cells, having poor electromechanical coupling and reduced contractile activity. These results could not be ascribed to a differential regulation of cardiac cell adhesion or proliferation by substrate stiffness. Finally, an overall effect of substrate stiffness on cardiac cell gene expression is demonstrated, with genes involved in cell-matrix interaction being upregulated on the softest substrate, while those related to inflammatory response being significantly activated on the stiffest.

\section{Materials and Methods}

\section{PCL film preparation and stiffness control}

Figure 1 shows a schematic illustration of the PCL materials prepared by cross-linking tetra-branched PCL with acrylate end-groups in the presence of linear PCL telechelicdiacrylates, according to a previously reported protocol. ${ }^{40}$ Briefly, twobranched and four-branched PCL were synthesized by $\varepsilon$ caprolactone ring-opening polymerization that was initiated

FIG. 1. Schematic illustration of preparation of cross-linked PCLs. Layers with various stiffness were obtained by simply mixing and curing two- and four-branched PCL with acrylate end-groups. PCL macromonomers were dissolved in xylene containing $\mathrm{BPO}$ and cured for $180 \mathrm{~min}$ at $80^{\circ} \mathrm{C}$, and the solution was injected between a glass slide with a $0.2-\mathrm{mm}$ thick Teflon spacer to obtain planar layers. BPO, benzoyl peroxide; PCL, poly- $\varepsilon$-caprolactone. Color images available online at www .liebertpub.com/tea

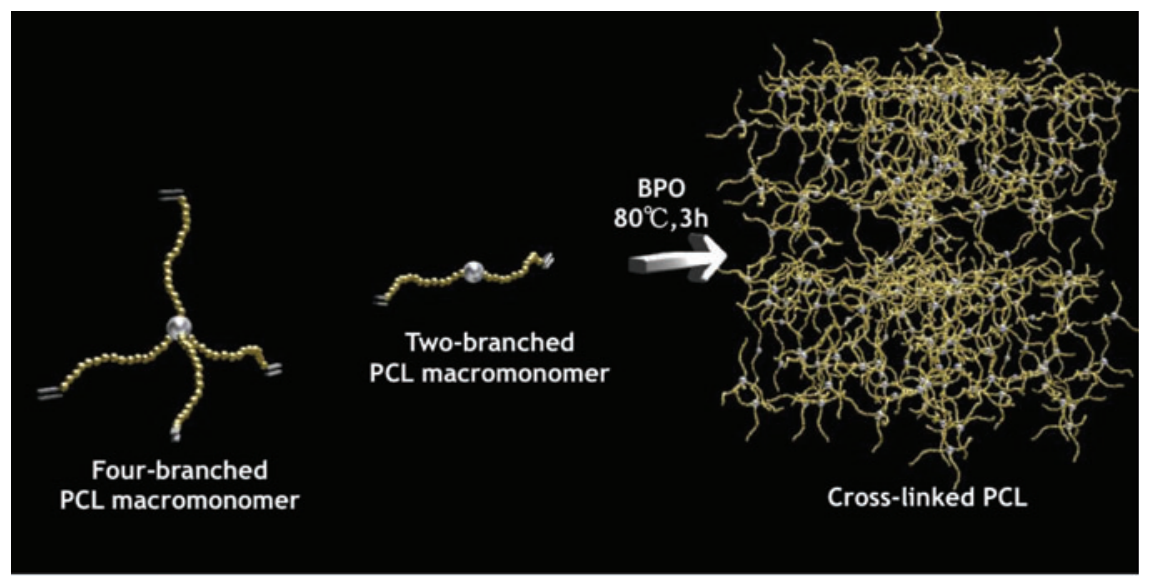


with tetramethylene glycol and pentaerythritol as initiators, respectively. Then, acryloyl chloride was reacted to the end of the branched chains. The structures and the molecular weights were estimated by ${ }^{1} \mathrm{H}$ NMR spectroscopy (JEOL) and gel permeation chromatography (Jasco International). The average degrees of polymerization of each branch on two-branched and four-branched PCL were 18 and 10, respectively. The obtained PCL macromonomers were then dissolved in xylene containing benzoyl peroxide, and the solution was injected between a glass slide with a $0.2-\mathrm{mm}$-thick Teflon spacer to prepare the substrate layers. The PCL macromonomers were cured for $180 \mathrm{~min}$ at $80^{\circ} \mathrm{C}$. The mechanical properties of the cross-linked materials were characterized by a tensile test (EZ-S 500N; Shimadzu). The contact angles on the PCL layers were also determined by a sessile drop method. They were measured $30 \mathrm{~s}$ after a water drop was placed on the surface at $37^{\circ} \mathrm{C}$.

\section{Murine neonatal cardiomyocyte extraction and characterization}

The study was performed on neonatal mice under the protocols approved by the institutional Animal Care and Use Committee of the University of Rome Tor Vergata (Rome, Italy). Cardiac cells were extracted from 1/3-dayold neonatal CD1 murine hearts $(n=30)$ by means of Trypsin enzymatic digestion (0.05\% Trypsin in a solution of $0.02 \%$ EDTA in phosphate buffer saline [PBS]) for $3 \mathrm{~h}$ at $4^{\circ} \mathrm{C}$, followed by incubation in collagenase II (1500 U; Worthington Biochemical Corporation) for $30 \mathrm{~min}$ at $37^{\circ} \mathrm{C}$. After filtration through a $0.70-\mu \mathrm{m}$ strainer (Falcon BD), the samples were collected and centrifuged for $5 \mathrm{~min}$ at $800 \mathrm{~g}$. Cells were resuspended in Claycomb medium (Sigma-Aldrich) supplemented with $10 \%$ fetal bovine serum (FBS; Lonza Group Ltd.), $100 \mathrm{IU} / \mathrm{mL}$ penicillin, and $4 \mathrm{mM}$ L-glutamine (Sigma-Aldrich) and seeded onto $2 \mu \mathrm{g} / \mathrm{mL}$ fibronectin (Biochrom AG) $/ 0.2 \%$ laminin in $0.02 \%$ gelatin (SigmaAldrich) precoated tissue culture polystyrene (TCPS) dishes and on PCL planar scaffolds. Cardiac cells were analyzed immediately after the extraction as described in Immunofluorescence staining and confocal microscopy section. The number of beating areas was calculated by counting 10 random fields under light microscope and the mean values obtained from three independent experiments were reported.

\section{Immunofluorescence staining and confocal microscopy}

Cells seeded on TCPS dishes or on PCL layers were fixed with $4 \%$ paraformaldehyde in PBS for $30 \mathrm{~min}$ at $4{ }^{\circ} \mathrm{C}$, and permeabilized with $0.1 \%$ TritonX-100 (Sigma-Aldrich) in PBS for 2 min at room temperature after 1, 3, and 7 days of culture. Cells were incubated with antibodies against $\alpha$ actinin (1:100; Sigma-Aldrich), GATA-4 (1:100; Santa Cruz Biotechnology), ki67 (Abcam), and myosin heavy chain (MF20-488; eBioscience) for $1 \mathrm{~h}$ at room temperature. The appropriate fluorophore-conjugated secondary antibodies were as follows: Alexa Fluor 488 goat-anti-rabbit and 546 goat-anti-mouse (Invitrogen Corp.). Nuclei were counterstained with 4-6-diamidino-2-phenylindole (DAPI; SigmaAldrich). Secondary antibodies in the absence of a specific primary antibody were used to exclude the occurrence of unspecific signals. The images were taken using a Leica
DMRB microscope equipped with a digital camera or using a confocal laser scanner microscope (Olympus FV 1000), after excitation at 405, 488, and $543 \mathrm{~nm}$ wavelengths for blue, green, and red channel acquisition, respectively. Volume reconstruction (3D rendering) and iso-surface for blue and red channels of xyz confocal image was performed using Imaris software (Bitplane).

Cell circle shape factor (or circularity index) was calculated as $4 \pi A / P^{2}$ on acquired images by manually outlining single cardiomyocytes as identified by $\alpha$-actinin staining ( $n=30 /$ sample) in ImageJ (National Institute of Health). Cardiomyocyte mean surface area was calculated on $\alpha$-actininpositive cells ( $n=30 /$ sample) by the same method using ImageJ software.

\section{Scanning electron microscopy analysis of the samples}

Cells grown for 7 days on PCL substrates were fixed in $4 \%$ PFA for $15 \mathrm{~min}$ at room temperature, dried under flow laminar hood, and prepared for scanning electron microscopy analysis as previously reported ${ }^{41}$ and examined using Hitachi S-4800 low-voltage scanning electron microscope.

\section{RNA extraction, real-time PCR, and PCR array}

Total RNA was extracted by TRIZOL Reagent (Gibco BRL). Retrotranscription was carried out with $2 \mu \mathrm{g}$ of RNA for each sample using reverse transcription (RT) Moloney murine leukemia virus (Invitrogen Corp.) in the presence of random hexamers. Real-time PCR was used to determine the expression profile of 90 key genes involved in different signal transduction pathways in Mus musculus. After synthesis of first-strand cDNAs, RT-PCR $(n=3)$ was performed by the 7500 Real-Time PCR System (Applied Biosystems) using the $\mathrm{RT}^{2}$ Profiler PCR Arrays Mouse Signal Transduction Pathway Finder (PAMM-014; Qiagen) and Mouse Extracellular Matrix and Adhesion Molecules (PAMM-013A) with the $\mathrm{RT}^{2}$ SYBR Green/ROX PCR Master mix (Qiagen) according to the manufacturer's protocol. The threshold cycle $(\mathrm{Ct})$ is defined as the fractional cycle number at which the fluorescence reaches 10-fold standard deviation of the baseline (from cycle 3 to cycle 12). The primers used to amplify cardiac-specific genes are the following: Nkx-2.5 (product size: 128) For: GAGCCTGGTAGGGAAAGAGC, Rev: GAGGGT GGGTGTGAAATCTG; GATA-4 (product size: 78) For: GAC ACACTGCCTTGTCTGGA， Rev: GCTGTGATCTGGTCTG AGGTC; Connexin 43 (product size: 74) For: AGGATTCA GGGGTAAAGGAAAC, Rev: GGCTGGGTTGGACAGTTA GT; and $\alpha$-cardiac actin (product size: 183) For: GTGGCT GGCTTCTCCTCTAA, Rev: AACACCTGCTTTCCTTCAC AA. The specificity of the SYBR PCR signal was confirmed by melt curve analysis. For the complete list of genes tested, please see Supplementary Table S1 (Supplementary Data are available online at www.liebertpub.com/tea).

\section{Statistical analysis}

The results are given as mean \pm standard deviation as obtained by counting $n$ fields per group in three independent experiments. The significance of differences in multigroup comparison was evaluated by one-way analysis of variance followed by unpaired Student's $t$-test. A final value of $p<0.05$ was considered statistically significant. 


\section{Results}

\section{Preparation of PCL layers with controlled stiffness}

Cross-linked tetra-branched PCL layers with linear PCL content varying between 0 and $100 \mathrm{wt} \%$ were successfully synthesized. As shown in Table 1, tensile tests showed compositionally dependent stiffness ranging from $\sim 0.91$ to 133.23 MPa, without changing their surface wettability that determines initial cell adhesion in the following experiments (Supplementary Fig. S1). Since branch number represents a parameter to adjust crystallinity and mechanical properties of the polymer networks, various suitable combinations can be obtained by simply mixing two- and four-branched macromonomers. Although the crystallinity of the crosslinked PCLs increased with increasing the two-branched PCL content, the elastic modulus of the layer with $50 \mathrm{wt} \%$ of two-branched PCL macromonomer was slightly smaller than that with $0 \mathrm{wt} \%$. This is because the netpoint density within the cross-linked PCL prepared from four-branched macromonomers only was the highest among the samples in this experiment. Thus, the unit length of the PCL macromonomers and netpoint density within the cross-linked PCL structure are the predominant contributors in controlling thermal and mechanical properties. Therefore, the stiffness could be successfully adjusted on demand by precisely tailoring the nanoarchitecture of semicrystalline PCL, while keeping a cell-compatible surface wettability. The layers displayed stiffness below $1 \mathrm{MPa}(0.91 \pm 0.08 \mathrm{MPa})$, or in the $\mathrm{MPa}$ range $(1.53 \pm 0.16,49.67 \pm 2.56$, and $133.23 \pm 8.67 \mathrm{MPa})$ and comparable surface wettability (Table 1).

\section{Substrate stiffness affects neonatal cardiomyocyte maturation but not adhesion}

Neonatal murine cardiomyocytes were extracted as previously described ${ }^{7}$ and seeded onto TCPS (virtually infinite stiffness) or PCL layers displaying $0.91 \pm 0.08,1.53 \pm 0.16$, $49.67 \pm 2.56$, and $133.23 \pm 8.67 \mathrm{MPa}$ stiffness. The number of cells expressing early cardiac commitment marker GATA-4 and mature cardiomyocyte-specific contractile proteins alpha actinin ( $\alpha$-actinin) and cardiac myosin heavy chain was evaluated after 1,3 , and 7 days of culture. The presence of $\alpha-$ actinin and myosin in the putative sarcomeric arrangement was considered as a hallmark of differentiated cardiomyo-

Table 1. Mechanical Properties and Surface Wettability of Layers Made of Cross-Linked POLY-E-CAPROLACTONES

\begin{tabular}{lcc}
\hline & \multicolumn{2}{c}{ Characterization at $37^{\circ} \mathrm{C}$} \\
\cline { 2 - 3 } $\begin{array}{l}\text { Composition of } 4-/ 2- \\
\text { branched PCL }(w t \%)\end{array}$ & $\begin{array}{c}\text { Elastic } \\
\text { modulus }(\mathrm{MPa})\end{array}$ & $\begin{array}{c}\text { Contact } \\
\text { angle }\left(^{\circ}\right)\end{array}$ \\
\hline $100 / 0$ & $1.53 \pm 0.16$ & $97.4 \pm 2.4$ \\
$50 / 50$ & $0.91 \pm 0.08$ & $98.7 \pm 1.6$ \\
$30 / 70$ & $49.67 \pm 2.56$ & $97.1 \pm 3.0$ \\
$0 / 100$ & $133.23 \pm 8.67$ & $97.7 \pm 3.1$ \\
\hline
\end{tabular}

The mechanical properties at $37^{\circ} \mathrm{C}$ were characterized by a tensile test. The contact angles on the films were determined by a sessile drop method. Compositionally dependent stiffness values were achieved, while keeping the surface wettability constant.

$\mathrm{PCL}$, poly-e-caprolactone. cytes (Fig. 2a). No significant differences in the adhesion rate of GATA-4+ cells were noticed $24 \mathrm{~h}$ after seeding on the layers having stiffness of $0.91,1.53$, and $49.67 \mathrm{MPa}$, while a smaller percentage of cells were expressing such marker on the stiffest substrate (133.23 MPa) (Fig. 2b). Nonetheless, after 3 days of culture, the number of GATA- 4 + cells increased on the stiffer surfaces, the higher percentage being encountered on the layer with $49.67 \mathrm{MPa}$ stiffness (Fig. 2a). A dramatic decrease in GATA-4 + expression was found on all the surfaces after 7 days, apart from the stiffest substrate, where its expression was stable over the culture. On the other hand, the number of $\alpha$-actinin + cells decreased in a timely fashion on all the surfaces tested, as expected for terminally differentiated cells. ${ }^{7}$ Nonetheless, although the only significant difference in $\alpha$-actinin + cell number after $24 \mathrm{~h}$ was detected on the 1.53 MPa surface (Fig. 2c); a larger number of positive cells could be found after 3 and 7 days on the softer substrates $(0.91$ and $1.53 \mathrm{MPa}$ ) as compared with the stiffer substrates (49.67 and $133.23 \mathrm{MPa}$; TCPS). Similar results were obtained by staining myosin heavy chain (data not shown). A thorough quantification of GATA- $4+$ and $\alpha$-actinin + proliferating cells by ki67 expression was performed on the polymers after 3 days of culture. The results obtained show that GATA- 4 undifferentiated cardiac cells retain a marked ability to proliferate as compared with terminally differentiated $\alpha$-actinin + cells, also outlining that no preferential proliferative effect is exerted by the substrates on cardiac cells (Fig. 2d). Cardiomyocytes on TCPS surface showed a similar behavior to those on 133.23 MPa substrate; thus, they were excluded from the following experiments.

\section{Cardiomyocyte morphology, sarcomere organization, and electromechanical coupling are impaired in long-term culture on stiff substrates}

As expected, the presence of cells expressing the properly assembled form of sarcomeric protein $\alpha$-actinin was detected on all the layers tested after 3 days of culture, although they appeared to be more scattered on the stiff substrates as compared with the softer substrates, where they were preferentially arranged in clusters (Fig. 3a). At the same time point, real-time PCR performed using primers specific for cardiac markers showed that alpha sarcomeric actin ( $\alpha$ sarcomeric actin) expression was enhanced by 1.8 -fold on the softest substrate (0.91 MPa), while cardiomyoblast marker GATA-4 was upregulated by 1.3 -fold on the stiffest (133.23 MPa). A significant downregulation of another marker of cardiomyoblasts, Nkx2.5, was found on the softest substrate, while only modest changes were detected for the gene encoding for connexin 43 (Fig. 3b). Nonetheless, the contractile apparatus was found disrupted in cardiomyocytes cultured for longer periods (7 days) onto the stiffer surfaces (49.67 and $133.23 \mathrm{MPa}$ ), while its pattern was preserved on the softer substrates (0.91 and $1.53 \mathrm{MPa}$ ) at the same time point (Fig. 4a and Supplementary Fig. S2). Additionally, the analysis of cell aspect demonstrated that lower values of circle shape factor and mean surface area (smaller cells with higher aspect ratio) are encountered in cells growing on softer substrates, while those adhering to the stiffer matrix have a higher mean values (bigger cells with low aspect ratio; Fig. 4c). At the same time point (7 days), the analysis of connexin 43 distribution within the cells, accounting for electromechanical coupling in fully differentiated cardiomyocytes, 


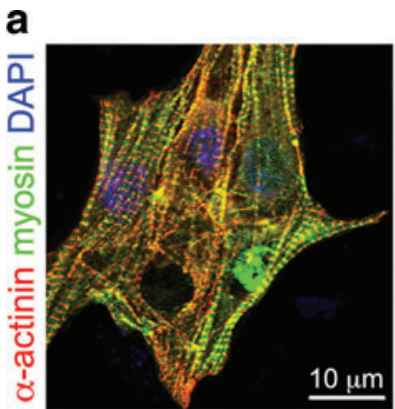

0.91

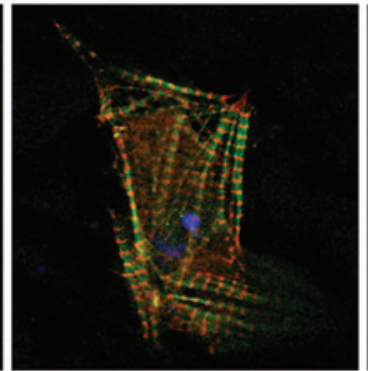

1.53

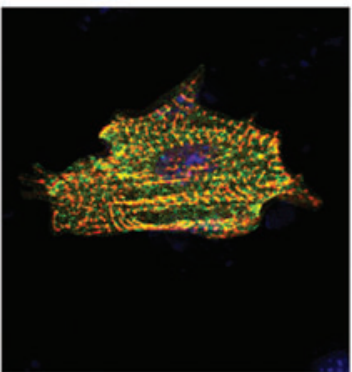

49.67

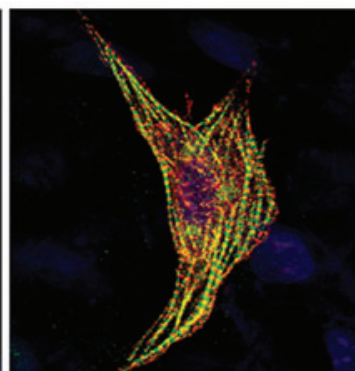

133.23

stiffness (MPa)

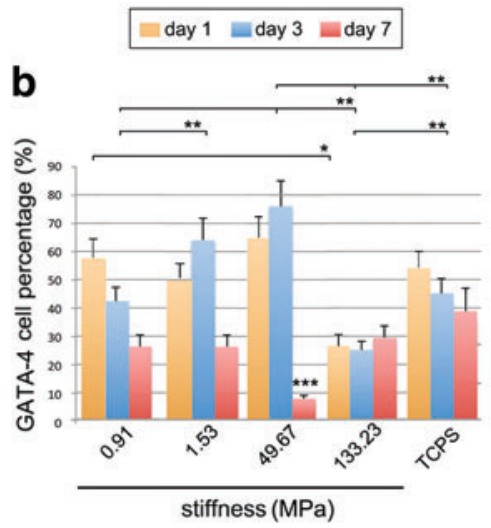

C

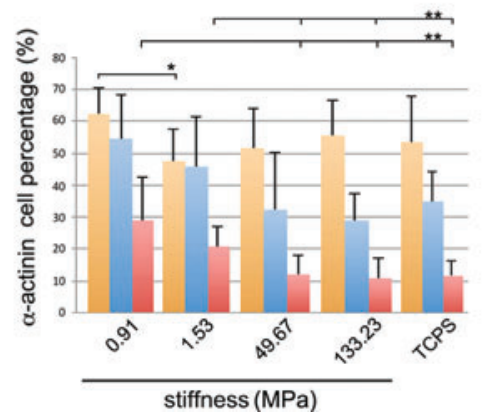

d

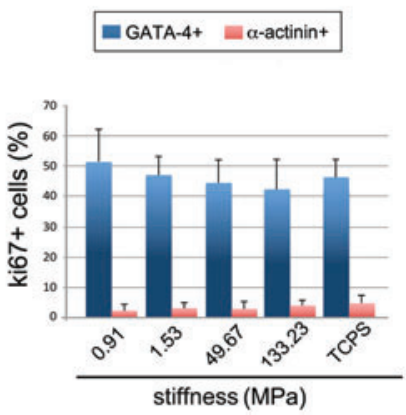

FIG. 2. Substrate stiffness affects neonatal cardiomyocyte maturation but not adhesion or proliferation. Murine neonatal cardiomyocytes were cultured onto PCL substrates having 0.91, 1.53, 49.67, and 133.23 MPa stiffness and TCPS (virtually infinite stiffness) for 1, 3, and 7 days. The presence of fully differentiated cardiomyocytes within the preparations was assessed by co-staining alpha actinin (red) and myosin heavy chain (myosin, green) in the typical striations (a). GATA-4 staining accounts for the presence of immature cardiomyocytes and nonmyocytes (b), while alpha actinin ( $\alpha$-actinin) decoration shows the percentage of cardiomyocytes displaying assembled sarcomere structure (c) on substrates having different stiffness values. The presence of proliferating cells among GATA- $4+$ or $\alpha$-actinin + cells was evaluated by ki67 co-staining after 3 days of culture on the different polymers (d). ${ }^{*} p<0.05$ after 1 day of culture; ${ }^{* *} p<0.05$ after 7 days of culture $(n=9)$; ${ }^{* * *} p<0.05$ vs. all the values at 1,3 and 7 days. TCPS, tissue culture polystyrene. Color images available online at www .liebertpub.com/tea

demonstrated that a fair membrane distribution could be found on cardiac cells grown onto the softer substrates $(0.91$ and $1.53 \mathrm{MPa}$ ) (Fig. 5a), while it was randomly distributed on the stiffer substrates. The correct distribution of connexin 43 on the softest substrate was also confirmed by $3 \mathrm{D}$ rendering at the confocal microscope (Fig. 5a, bottom and Supplementary Video S1). The same analysis allowed demonstrating functional $\alpha$-actinin assembly (Fig. 5b) and vinculin expression in cardiomyocytes grown on the softer substrates (Fig. 5c). Cardiomyocyte beating activity was also assessed on the substrates having different overall stiffness, and the beating areas were quantified by light microscopy. The number of beating areas in the time frame considered $(1,3,4$, and 7 days) was found to be significantly higher on the softer substrates $(0.91 \mathrm{MPa})$, while the lowest number of beating areas could be found on the stiffest substrates (133.23 MPa) (Fig. 5d and Supplementary Videos S2 and S3).

\section{Cardiac cell gene expression is regulated by substrate stiffness}

A thorough analysis of gene expression in cardiac cells grown on PCL layers was performed by analyzing 168 genes involved in different signaling pathways and in extracellular matrix formation by PCR array. On this purpose, cardiomyocytes were seeded on 0.91 and $133.23 \mathrm{MPa}$ substrates for 3 days and total RNA was extracted. Ex vivo extracted cardiomyocytes were used as controls (data not shown). Supplementary Figure 3 illustrates a number of genes differentially regulated in cells grown on the films, grouped per function and/or pathway (for complete gene array information, please refer to Supplementary Table S1). Moreover, Figure 6 shows the results of a bioinformatics analysis of gene expression, as obtained by the software GENEMANIA (www.genemania.org). The network in Figure 6a demonstrates that the genes upregulated on $0.91 \mathrm{MPa}$ stiffness are mostly related to cell adhesion (laminins) and extracellular matrix remodeling (MMPs and TIMPs). On the contrary, Figure $6 \mathrm{~b}$ shows that mostly genes involved in the regulation of inflammation response are significantly upregulated on the stiffest substrate (133.23 MPa).

\section{Discussion}

The interaction of scaffolds and cells has been so far considered mainly in terms of cell adhesion, proliferation, and 


\section{stiffness(MPa)}

a
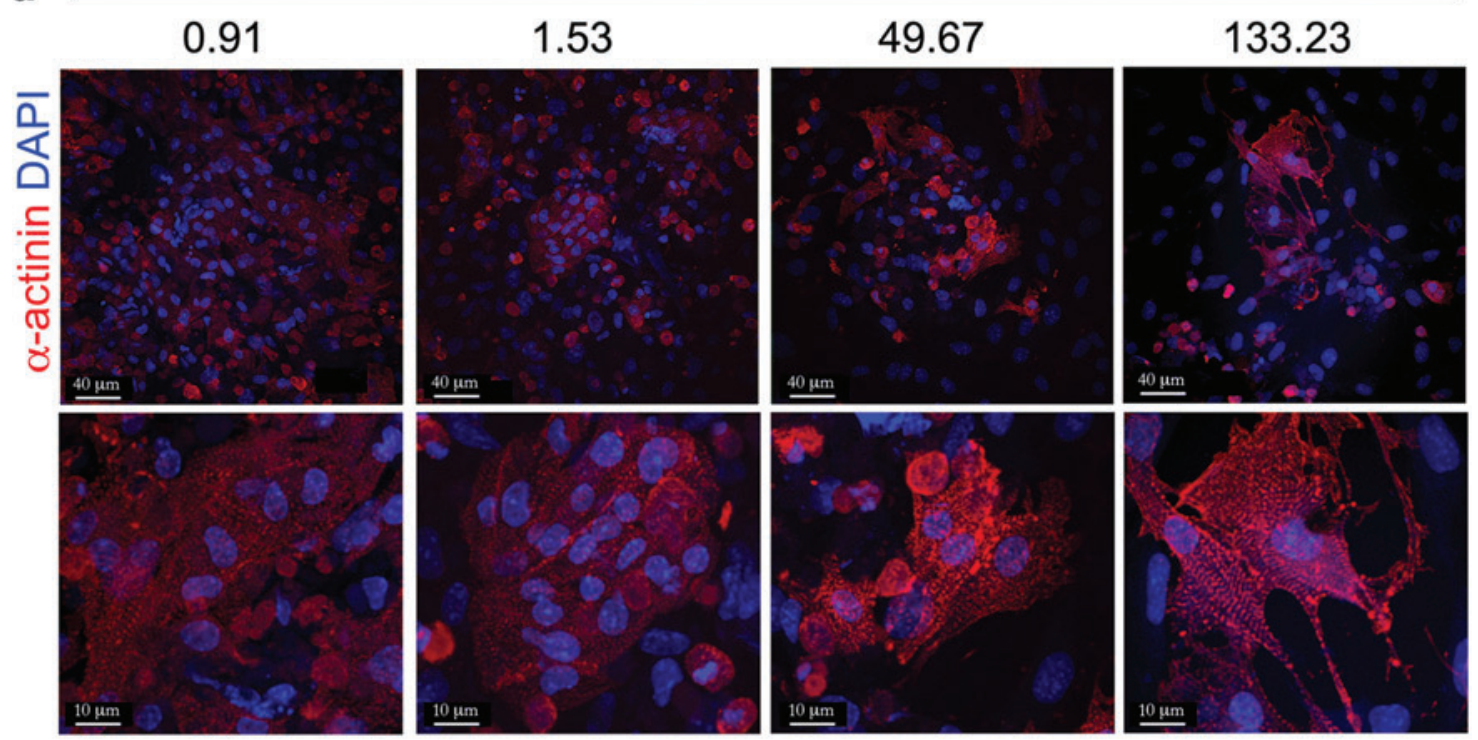

\section{b}
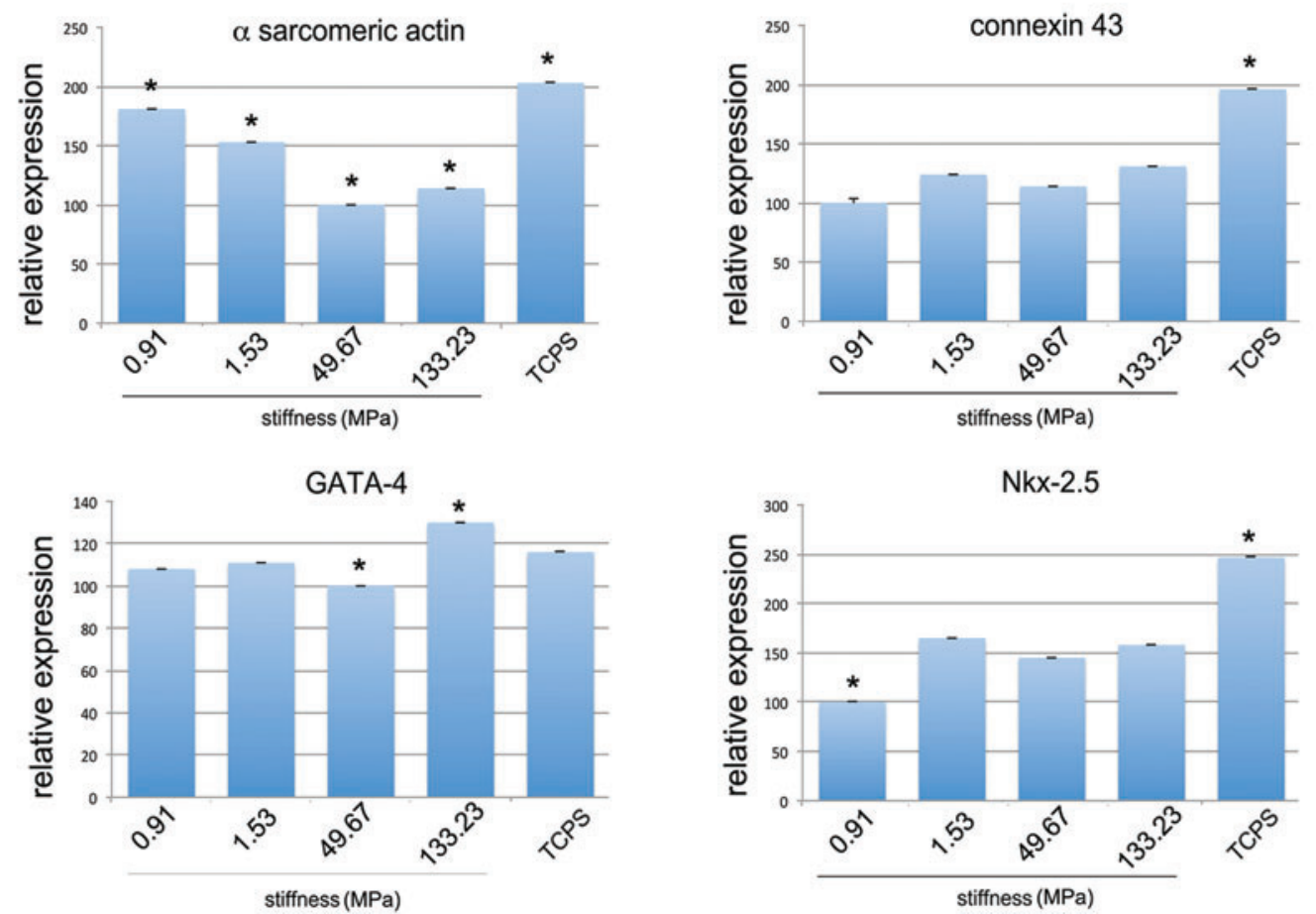

FIG. 3. Neonatal cardiomyocytes express coherent sarcomere banding in short-term culture on substrates with different stiffness values. Neonatal cardiomyocytes cultured for 3 days onto substrates having stiffness below $1 \mathrm{MPa}(0.91 \mathrm{MPa})$ or in the MPa range $(1.53,49.63$, and $133.23, \mathrm{MPa})$ display sarcomere banding, as highlighted by $\alpha$-actinin staining (red). Nuclei are counterstained in blue (DAPI) (a). At the same time point, real-time PCR analysis was performed using primers specific for markers alpha sarcomeric actin, connexin 43, GATA-4, and Nkx-2.5 on cardiac cells cultured on PCL substrates as compared with TCPS dishes (b). The results are representative of three independent experiments; ${ }^{*} p<0.05$. DAPI, 4-6-diamidino-2phenylindole. Color images available online at www.liebertpub.com/tea

differentiation, ${ }^{42}$ while only in the last few years the possibility that synthetic substrates-designed to provide implanted cells with a favorable microenvironment-could integrate or interfere with cell function in vivo has been acknowledged. ${ }^{43}$ In fact, at the basis of tissue engineering paradigm lays the idea that a scaffold to be used in tissue regeneration should favor new tissue formation without interfering with organ function. ${ }^{27}$ Nonetheless, scaffold's physical and mechanical properties have been shown to affect cell survival, ${ }^{2}$ proliferation, ${ }^{44}$ migration, ${ }^{5}$ and eventually 

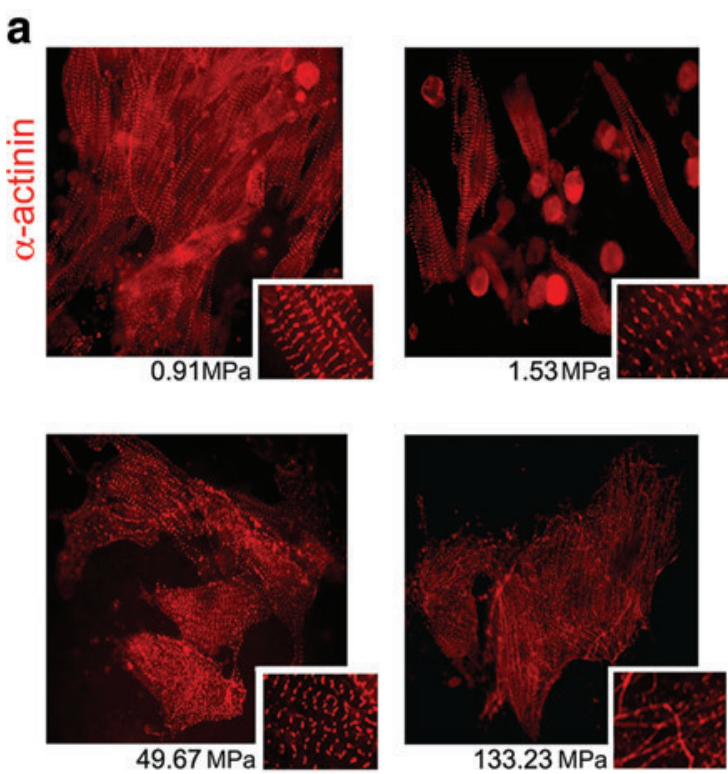

b
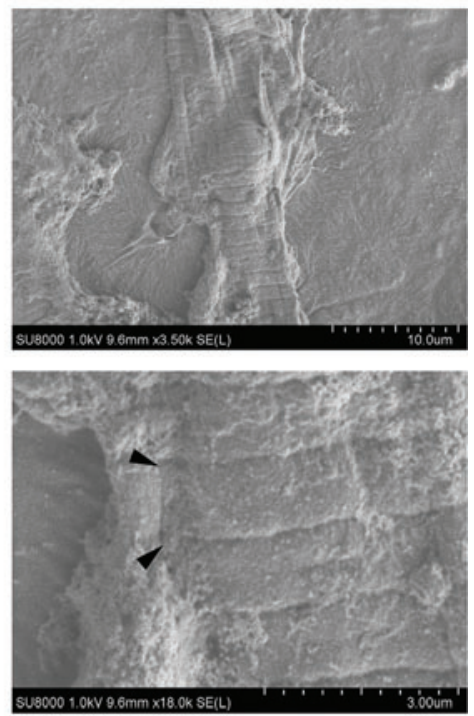

c

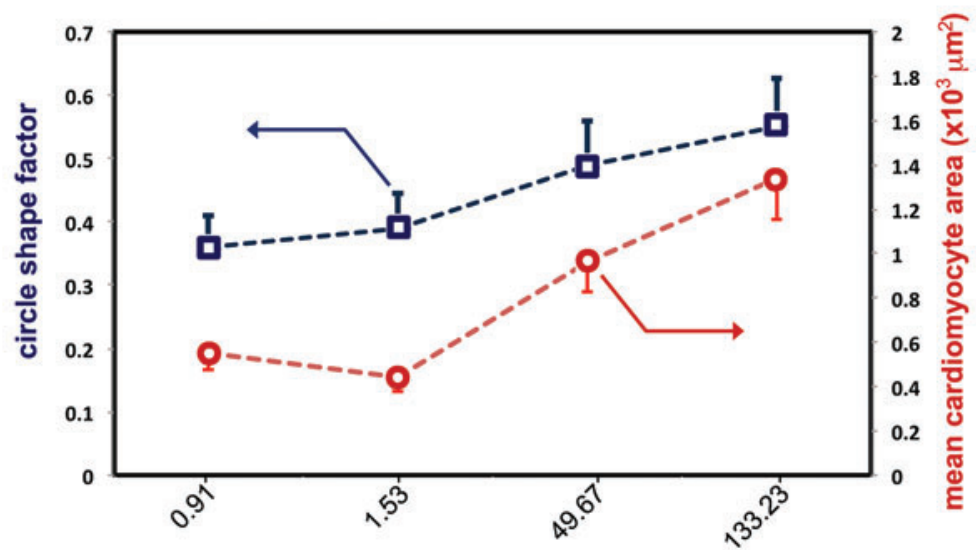

STIFFNESS (MPa)

FIG. 4. Long-term culture of neonatal cardiomyocytes discloses differences in cell response to substrate stiffness. Sarcomeric actinin ( $\alpha$-actinin, red) staining of neonatal cardiac cells grown for 7 days onto substrates having different stiffness values shows that the contractile apparatus is perturbed in cells growing onto stiff matrix (133.23 MPa), while on softer substrates $(0.9$ and $1.53 \mathrm{MPa})$ sarcomeric striations are still well organized (a). The insets show a higher magnification of the sarcomeric structure. Scanning electron microscopy micrographs confirm the presence of cells having correct sarcomeric organization on the softest substrate (b). In the bottom picture, arrowheads indicate the sarcomere. Also, cells grown on substrates having different stiffness values display rather different shapes, as measured by circle shape factor, and different mean area (c). In fact, cells on stiffer substrates acquire a flat morphology, with a higher circle shape factor and mean surface area (c). Circle shape factor and mean cardiomyocyte area were calculated by manually outlining $\alpha$-actinin-positive cells in Image $(n=50 /$ each sample). The results are reported as mean \pm S.D. Dashed lines are guide for the eyes. Color images available online at www.liebertpub.com/tea

differentiation. ${ }^{3,4}$ These parameters have been regarded to act cooperatively with biological cues to maintain cell phenotype and function ${ }^{45}$ or direct stem cell commitment. ${ }^{7}$ Recently, evidence has been given that stem and mature cells can sense the stiffness of the substrate they grow on and perceive this parameter as physiological when it matches tissue-specific values. ${ }^{3,16}$ In this context, the indication that embryonic quail and chicken cardiomyocyte beating activity is preserved on scaffolds displaying cardiac-like rigidity appears interesting. ${ }^{16}$ Additionally, neonatal rat ventricular cardiomyocytes have been shown to proceed to cell matu- ration and produce higher mechanical force on matrices having myocardial-like stiffness $(10 \mathrm{kPa}),{ }^{17}$ while higher values $(144 \mathrm{kPa})$ led to a reduced troponin I staining and poor electrical excitability. Such experiments were justified by the evidence that the local Young's modulus for adult rat heart tissue ranges from 11.9 to $46.2 \mathrm{kPa}(25.6 \pm 15.9 \mathrm{kPa}){ }^{46}$ while infarcted myocardium stiffness has been reported to be around $55 \pm 15 \mathrm{kPa}$ in Lewis rats. ${ }^{19}$

The use of synthetic scaffolds having elastomeric properties, being able to comply with the contractile activity of the organ, has been suggested for cardiac tissue repair. ${ }^{30,47}$ While 
stiffness (MPa)
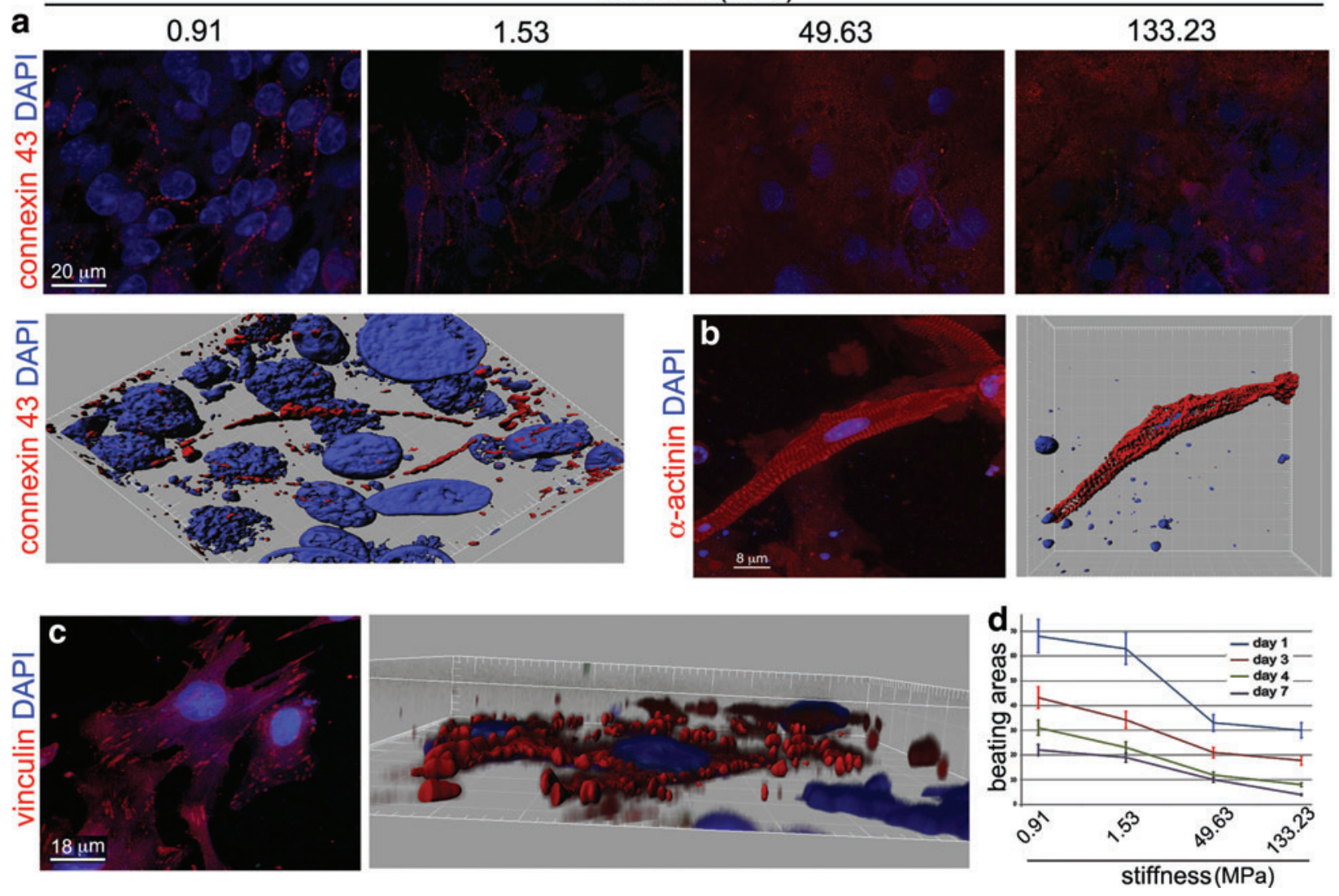

FIG. 5. Substrate stiffness perturbs cardiomyocyte electro-mechanical coupling. Connexin 43 staining (red), accounting for cell-to-cell interaction and electromechanical coupling in cardiomyocytes, appears functionally expressed on cell membrane in cardiomyocytes grown onto softer $(0.91$ and $1.53 \mathrm{MPa})$ substrates for 7 days, while its expression is scattered in those cultured onto stiffer (49.63 and 133.23 MPa) substrates at the same time point (a). The appropriateness of connexin 43 expression on softer substrates is confirmed in 3D confocal images $(\mathbf{a}$, bottom). A representative image highlighting the $\alpha$-actinin staining (red) in cardiomyocytes grown for 7 days onto $0.91 \mathrm{MPa}$ surface and its 3D confocal reconstruction (b). Functional cell-substrate interactions are present on soft substrates $(0.91 \mathrm{MPa})$, as demonstrated by vinculin staining (red) and its 3D confocal reconstruction (c). Nuclei are counterstained with DAPI (blue). The occurrence of spontaneous beating areas within cardiomyocyte culture on the substrates tested demonstrated that a significantly higher number of beating areas could be found onto the softer $(0.91$ and $1.53 \mathrm{MPa})$ substrates, as compared with stiffer substrates (49.63 and 133.23 MPa). This evidence was confirmed after 1 , 3,4 , and 7 days in culture (d). 3D, three-dimensional. Color images available online at www.liebertpub.com/tea

synthetic polymers can be easily manufactured to tailor their $3 \mathrm{D}$ structure in the nano- and microscale to better reproduce cardiac anisotropy, ${ }^{4}$ as a bulk they usually display a Young's modulus that is far larger than that measured for body tissues. Among them, PCL is an elastomeric polyester already approved for biomedical applications by Food and Drug Administration, and already proven to be suitable for cell culture. ${ }^{38}$ Moreover, its longer degradation time as compared with poly-lactide makes it appealing for tissue engineering applications. ${ }^{48,49}$

Thus, in the present investigation, elastomeric PCL substrates having different Young's modulus values (0.91, 1.53, 49.67 , and $133.23 \mathrm{MPa}$ ) were used to culture neonatal murine cardiac cells and systematically investigate the effects of substrate stiffness on cardiomyocyte phenotype. Our data show that the expression of a number of genes can be significantly altered by substrate stiffness in cardiac cells. In particular, genes involved in cell-matrix interaction (lama1, lama2, fn1, vtn, integrins, etc.) and extracellular matrix re- modeling (MMPs and TIMPs) were found upregulated on the softest substrate $(0.91 \mathrm{MPa})$ as compared with the stiffest substrate (133.23 MPa). On the other hand, among the genes found upregulated on the latter surface, the presence of a number of those involved in immune response control (IL1a, IL2, IL2ra, tnf, fas, fasl, etc.) and inflammatory cell recruitment was detected. These data suggest that in a heterogeneous preparation of cardiac cells obtained from neonatal murine heart, in which cardiomyocytes, cardiac fibroblasts, endothelial, smooth muscle, and inflammatory cells are present, those cells can display a cell-specific response to matrix mechanics. Such a concept was already proposed by a number of independent investigations, showing that not all the cells are mechanosensitive and among those that are able to feel substrate mechanical properties, specific responses can be triggered. 3,4,9,26 Accordingly, the response of heterogeneous cell preparations to substrate mechanophysical properties is likely to be far more complex than what is thought, 3,16 with different cell subsets displaying rather 

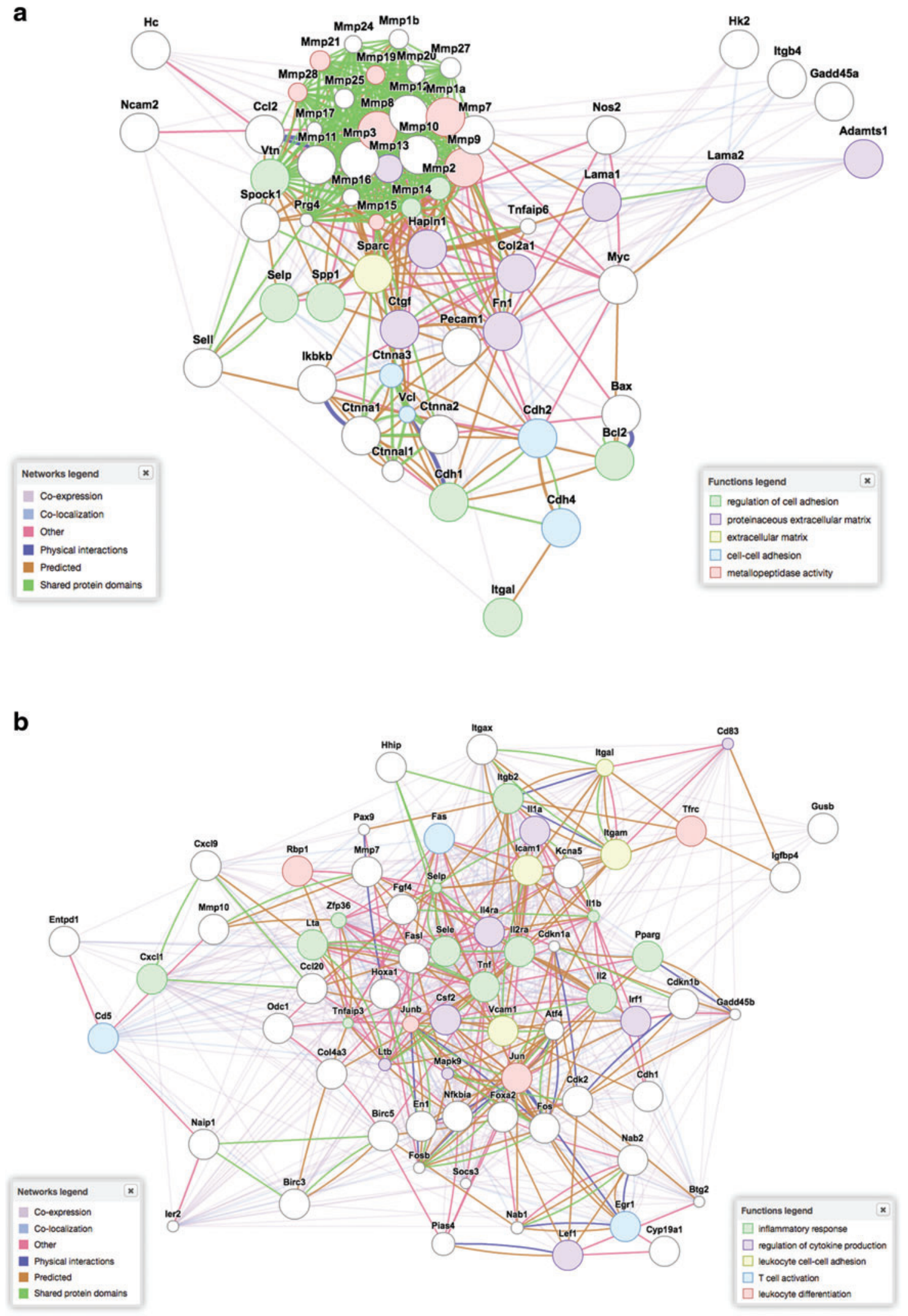

FIG. 6. Gene expression regulation by substrate stiffness in murine neonatal cardiomyocytes. Computational gene analysis obtained by plotting in GENEMANIA software (www.genemania.org) shows the results of two PCR array sets containing 186 genes of interest in cardiac cells grown for 3 days onto PCL layers having 0.91 (a) and 133.23 (b) MPa stiffness. Only genes differentially regulated on any of the two polymers are plotted (for the complete list of genes tested, please refer to Supplementary Table S1). Network legend highlights the presence of physical interactions, co-expression, or co-localization of the products of the genes differentially regulated. Function legend underlines the participation of the gene products differentially regulated to specific molecular pathways. Color images available online at www.liebertpub.com/tea 
different sensitivity. In this context, the evidence that stiff substrates, in the absence of biological cues, can provoke a raise in immune response appears in good agreement with previous reports showing that the compliance of the microenvironment can interfere with neutrophil migration during the chemotactic process, ${ }^{50,51}$ even though our result was obtained using a preparation that is supposed to contain a very limited percentage of inflammatory cells.

As compared with freshly extracted cells, a significant upregulation of genes involved in cell survival, like tert, Nos2, and bax, occurred when cardiac cells are cultured for 3 days on TCPS dishes, while a concomitant downregulation of genes responsible for cell proliferation (jun, fos, cdk2, $c d k n 1 b$, and egr-1) was detected in cultured cells in comparison to ex vivo cells. Such a gene pattern can be hardly ascribed to a single event (i.e., ischemia, hypertrophy, angiogenesis, etc.), ${ }^{52,53}$ but it could be compatible with cardiac cell adaptation to the new in vitro conditions. Also, differences in cell morphology, phenotype, sarcomere structure, and function could be found when cardiomyocytes were cultured on substrates with different stiffness values. In fact, a differential expression of GATA-4, Nkx-2.5, alpha actinin ( $\alpha$-actinin), and myosin heavy chain could be detected. While the number of early cardiomyoblast markers GATA-4- and Nkx-2.5 was found to increase with the substrate stiffness (maximum value on 49.67 and $133.23 \mathrm{MPa}$ surfaces after 1 and 3 days), mature $\alpha$-actinin-positive cells were positively selected after 3 and 7 days on the softer substrates $(0.91$ and $1.53 \mathrm{MPa})$, when a physiological decrease in cardiomyocyte percentage is expected. ${ }^{7}$ Indeed, more than $85 \%$ of differentiated cardiomyocytes were retained on the softer surfaces after 3 days as compared with day 1 , while only $60 \%$ of them could be found on the stiffer substrates. These effects were not mediated by cell adhesion, since the slight differences encountered after $24 \mathrm{~h}$ of culture in GATA-4- and $\alpha$-actinin-positive cells could not explain such results. Also, these results could not be ascribed to a differential effect of substrate mechanics on cardiac cell proliferation, since no significant differences in proliferating GATA-4- or $\alpha$-actinin-positive cells could be found on PCL surfaces. Strikingly, a marked difference in the quality of sarcomere structure was noticed at longer time points ( 3 and 7 days) as an effect of substrate stiffness. In fact, intact sarcomere bands were retained on softer substrates, while their structure was perturbed in cardiomyocytes grown on the stiffer substrates (49.67-133.23 MPa). Moreover, cardiomyocyte cell shape appeared to be different between the softer and the stiffer substrates, as quantified by circle shape factor and connexin 43 staining, with cells grown on the softer substrates being more elongated and displaying correct electromechanical connections. Consistently, the number of contractile areas after 1,3,4, and 7 days after seeding was found to be inversely correlated to the substrate stiffness. Altogether, these data suggest that neonatal cardiomyocytes preferentially acquire and retain a mature phenotype on substrates having Young's modulus around $1 \mathrm{MPa}$, while stiffer surfaces are probably not suitable to sustain their function.

\section{Conclusions}

Our data demonstrate that cardiomyocyte phenotype and maturation can be affected by the substrate stiffness and that a higher percentage of mature cardiomyocytes having proper sarcomere assembly, and thus beating activity, can be selected by using substrates having Young's modulus around $1 \mathrm{MPa}$. Nonetheless, the possibility that distinct cell types respond differently to matrix mechanics should be taken into account when scaffolds for a specific application, like cardiac tissue engineering, are to be prepared.

\section{Acknowledgments}

The present work was supported by the Japan Society for the Promotion of Science (JSPS) through the "Funding Program for World-Leading Innovative R\&D on Science and Technology (FIRST Program)," the World Premier International (WPI) Research Center Initiative and by the "Nanotechnology Network Project" of the Ministry of Education, Culture, Sports, Science and Technology (MEXT), Japan. The authors would like to thank Shoko Kajiwara and the Centre of Advanced Microscopy (CAM), Department of Biology, University of Rome Tor Vergata, for the skillful assistance.

\section{Disclosure Statement}

The authors have no competing financial interests to disclose.

\section{References}

1. Freed, L.E., Engelmayr, G.C. Jr, Borenstein, J.T., Moutos, F.T., and Guilak, F. Advanced material strategies for tissue engineering scaffolds. Adv Mater 21, 3410, 2009.

2. Guilak, F., Cohen, D.M., Estes, B.T., Gimble, J.M., Liedtke, W., and Chen, C.S. Control of stem cell fate by physical interactions with the extracellular matrix. Cell Stem Cell 5, 17, 2009.

3. Engler, A.J., Sen, S., Sweeney, H.L., and Discher, D.E. Matrix elasticity directs stem cell lineage specification. Cell 126, 677, 2006.

4. Forte, G., Carotenuto, F., Pagliari, F., Pagliari, S., Cossa, P., Fiaccavento, R., Ahluwalia, A., Vozzi, G., Vinci, B., Serafino, A., Rinaldi, A., Traversa, E., Carosella, L., Minieri, M., and Di Nardo, P. Criticatility of the biological and physical stimuli array inducing resident stem cell determination. Stem Cells 26, 2093, 2008.

5. Tse, J.R., and Engler, A.J. Stiffness gradients mimicking in vivo tissue variation regulate mesenchymal stem cell fate. PLoS One e15978, 2011.

6. Lozoya, O.A., Wauthier, E., Turner, R.A., Barbier, C., Prestwich, G.D., Guilak, F., Superfine, R., Lubkin, S.R., and Reid, L.M. Regulation of hepatic stem/progenitor phenotype by microenvironment stiffness in hydrogel models of the human liver stem cell niche. Biomaterials 32, 7389, 2011.

7. Pagliari, S., Vilela-Silva, A.C., Forte, G., Pagliari, F., Mandoli, C., Vozzi, G., Pietronave, S., Prat, M., Licoccia, S., Ahluwalia, A., Traversa, E., Minieri, M., and Di Nardo, P. Cooperation of biological and mechanical signals in cardiac progenitor cell differentiation. Adv Mater 23, 514, 2011.

8. Vailhe, B., Ronot, X., Tracqui, P., Usson, Y., and Tranqui, L. In vitro angiogenesis is modulated by the mechanical properties of fibrin gels and is related to alpha(v)beta3 integrin localization. In vitro Cell Dev Biol Anim 33, 763, 1997.

9. Wang, H.B., Dembo, M., and Wnag, Y.L. Substrate flexibility regulates growth and apoptosis of normal but not transformed cells. Am J Physiol Cell Physiol 279, C1345, 2000. 
10. Gaca, M.D., Zhou, X., Issa, R., Kiriella, K., Iredale, J.P., and Benyon, R.C. Basement membrane-like matrix inhibits proliferation and collagen synthesis by activated rat hepatic stellate cells: evidence for matrix-dependent deactivation of stellate cells. Matrix Biol 22, 229, 2003.

11. Peyton, S.R., and Putnam, A.J. Extracellular matrix rigidity governs smooth muscle cell motility in a biphasic fashion. J Cell Physiol 204, 198, 2005.

12. Wang, Y.K., Yu, X., Cohen, D.M., Wozniak, M.A., Yang, M.T., Gao, L., Eyckmans, J., and Chen, C.S. Bone morphogenetic Protein-2-induced signaling and osteogenesis is regulated by cell shape, RhoA/ROCK, and cytoskeleton tension. Stem Cells Dev 21, 1176, 2012.

13. Xu, B., Song, G., Ju, Y., Li, X., Song, Y., and Watanabe, S. RhoA/ROCK, cytoskeletal dynamics and focal adhesion kinase are required for mechanical stretch-induced tenogenic differentiation of human mesenchymal stem cells. J Cell Physiol 227, 2722, 2012.

14. McBeath, R., Pirone, D.M., Nelson, C.M., Bhadriraju, K., and Chen, C.S. Cell shape, cytoskeletal tension, and RhoA regulate stem cell lineage commitment. Dev Cell 6, 483, 2004.

15. Kim, T.J., Seong, J., Ouyang, M., Sun, J., Lu, S., Hong, J.P., Wang, N., and Wang, Y. Substrate rigidity regulates $\mathrm{Ca} 2+$ oscillation via RhoA pathway in stem cells. J Cell Physiol 218, 285, 2009.

16. Engler, A.J., Carag-Krieger, C., Johnson, C.P., Raab, M., Tang, H.Y., Speicher, D.W., Sanger, J.W., Sanger, J.M., and Discher, D.E. Embryonic cardiomyocytes beat best on a matrix with heart-like elasticity: scar-like rigidity inhibits beating. J Cell Sci 121, 3794, 2008.

17. Jacot, J.G., McCulloch, A.D., and Omens, J.H. Substrate stiffness affects the functional maturation of neonatal rat ventricular myocytes. Biophys J 95, 3479, 2008.

18. Engler, A.J., Griffin, M.A., Sen, S., Bönnemann, C.G., Sweeney, H.L., and Discher, D.E. Myotubes differentiate optimally on substrates with tissue-like stiffness: pathological implications for soft or stiff microenvironments. J Cell Biol 166, 877, 2004.

19. Berry, M.F., Engler, A.J., Woo, Y.J., Pirolli, T.J., Bish, L.T., Jayasankar, V., Morine, K.J., Gardner, T.J., Discher, D.E., and Sweeney, H.L. Mesenchymal stem cell injection after myocardial infarction improves myocardial compliance. Am J Physiol Heart Circ Physiol 290, H2196, 2006.

20. Wang, X., Hu, Q., Nakamura, Y., Lee, J., Zhang, G., From, A.H., and Zhang, J. The role of the sca-1+/CD31- cardiac progenitor cell population in postinfarction left ventricular remodeling. Stem Cells 24, 1779, 2006.

21. Breitbach, M., Bostani, T., Roell, W., Xia, Y., Dewald, O., Nygren, J.M., Tienmann, K., Bohlen, H., Hescheler, J., Welz, A., Bloch, W., Jacobsen, S.E., and Fleischmann, B.K. Potential risks of bone marrow cell transplantation into infarcted hearts. Blood 110, 1362, 2007.

22. Den Haan, M., Grauss, R.W., Smits, A.M., Winter, E.M., van tuyn, J., Pijnappels, D.A., Steendijk, P., Gittenberger-DeGroot, A.C., van der Laarse, A., Fibbe, W.E., de Vries, A.A., Schalij, M.J., Doevendans, P.A., Goumans, M.J., and Atsma, D.E. Cardiomyogenic differentiation-independent improvement of cardiac function by human cardiomyocyte progenitor cell injection in ischemic mouse hearts. J Cell Mol Med 2011 [Epub ahead of print]; DOI: 10.1111/j.15824934.2011.01468.x.

23. Swaminathan, V., Mythreye, K., O’Brien, E.T., Berchuck, A., Blobe, G.C., and Superfine, R. Mechanical stiffness grades metastatic potential in patient tumor cells and in cancer cell lines. Cancer Res 71, 5075, 2011.

24. Indra, I., and Beningo, K.A. An in vitro correlation of metastatic capacity, substrate rigidity, and ECM composition. J Cell Biochem 112, 3151, 2011.

25. Liang, Y., Jeong, J., De Volder, R.J., Cha, C., Wang, F., Tong, Y.W., and Kong, H. A cell-instructive hydrogel to regulate malignancy of 3D tumor spheroids with matrix rigidity. Biomaterials 32, 9308, 2011.

26. Georges, P.C., and Janmey, P.A. Cell type-specific response to growth on soft materials. J Appl Physiol 98, 1547, 2005.

27. Forte, G., Pagliari, S., Pagliari, F., Ebara, M., Di Nardo, P., and Aoyagi, T. Towards the generation of patient-specific patches for cardiac repair. Stem Cell Rev 2011 [Epub ahead of print]; DOI: 10.1007/s12015-011-9325-8.

28. Li, Z., and Guan, J. Hydrogels for cardiac tissue engineering. Polymers 3, 740, 2011.

29. Chen, Q-Z., Bismarck, A., Hansen, U., Junaid, S., Tran, M.Q., Harding, S.E., Ali, N.N., and Boccaccini, A.R. Characterisation of a soft elastomer poly (glycerol sebacate) designed to match the mechanical properties of myocardial tissue. Biomaterials 29, 47, 2008.

30. Engelmayr, G.C., Jr., Cheng, M., Bettinger, C.J., Borenstein, J.T., Langer, R., and Freed, L.E. Accordion-like honeycombs for tissue-engineering of cardiac anisotropy. Nat Mater 7, 1719, 2008.

31. Di Nardo, P., Forte, G., Ahluwalia, A., and Minieri, M. Cardiac progenitor cells: potency and control. J Cell Physiol 224, 590, 2010.

32. Badylak, S.F., and Gilbert, T.W. Immune response to biologic scaffold materials. Semin Immunol 20, 109, 2008.

33. Di Felice, V., De Luca, A., Serradifalco, C., Di Marco, P., Verin, L., Motta, A., Guercio, A., and Zummo, G. Adult stem cells, scaffolds for in vivo and in vitro myocardial tissue engineering. Ital J Anat Embryol 115, 65, 2010.

34. Leor, J., Aboulafia-Etzion, S., Dar, A., Shapiro, L., Barbash, I.M., Battler, A., Granot, Y., and Cohen, S. Bioengineered cardiac grafts-a new approach to repair the infarcted myocardium? Circulation 102, 56, 2000.

35. Li, R.K., Yau, T.M., Weisel, R.D., Mickle, D.A.G., Sakai, T., Sakai, T., Choi, A., and Jia, Z.Q. Construction of a bioengineered cardiac graft. J Thorac Cardiovasc Surg 119, 368, 2000.

36. Jockenhoevel, S., Zund, G., Hoerstrup, S.P., Chalabi, K., Sachweh, J.S., Demircan, L., Messmer, B.J., and Turina, M. Fibrin gel-advantages of a new scaffold in cardiovascular tissue engineering. Eur J Cardiothorac Surg 19, 424, 2001.

37. Blan, N.R., and Birla, R.K. Design and fabrication of heart muscle using scaffold-based tissue engineering. J Biomed Mater Res A 86, 195, 2008.

38. Soliman, S., Pagliari, S., Rinaldi, A., Forte, G., Fiaccavento, R., Pagliari, F., Minieri, M., Di Nardo, P., Licoccia, S., and Traversa, E. Multiscale 3D scaffolds for soft tissue engineering via multimodal electrospinning. Acta Biomater 6, 1227, 2010.

39. Mariani, M., Rosatini, F., Vozzi, G., Previti, A., and Ahluwalia, A. Characterization of tissue-engineered scaffolds microfabricated with PAM. Tissue Eng 12, 547, 2006.

40. Ebara, M., Uto, K., Idota, N., Hoffman, J.M., and Aoyagi, T. Shape-memory surface with dynamically tunable nanogeometry activated by body heat. Adv Mater24, 273, 2012.

41. Mandoli, C., Pagliari, F., Pagliari, S., Forte, G., Di Nardo, P., Licoccia, S., and Traversa, E. Stem cell aligned growth induced by $\mathrm{CeO}_{2}$ nanoparticles in PLGA scaffolds with 
improved bioactivity for regenerative medicine. Adv Funct Mater 20, 1617, 2010.

42. Janmey, P.A., and Miller, R.T. Mechanisms of mechanical signaling in development and disease. J Cell Sci 124, 9, 2011.

43. Leor, J., Amsalem, Y., and Cohen, S. Cells, scaffolds, and molecules for myocardial tissue engineering. Pharmacol Ther 105, 151, 2005.

44. Kress, S., Neumann, A., Weyand, B., and Kasper, C. Stem Cell Differentiation Depending on Different Surfaces. Adv Biochem Eng Biotechnol 126, 263, 2012.

45. Nadzir, M.M., Kino-Oka, M., Maruyama, N., Sato, Y., Kim, M.H., Sugawara, K., and Taya, M. Comprehension of terminal differentiation and dedifferentiation of chondrocytes during passage cultures. J Biosci Bioeng 112, 395, 2011.

46. Bhana, B., Lyer, R.K., Chen, W.L., Zhao, R., Sider, K.L., Likhitpanichkul, M., Simmons, C.A., and Radisic, M. Influence of substrate stiffness on the phenotype of heart cells. Biotechnol Bioeng 105, 1148, 2010.

47. Vunjak-Novakovic, G., Tandon, N., Godier, A., Maidhof, R., Marsano, A., Martens, T.P., and Radisic, M. Challenges in cardiac tissue engineering. Tissue Eng Part B Rev 16, 169, 2010.

48. Sung, H-J., Meredith, C., Johnson, C., and Galis, Z.S. The effect of scaffold degradation rate on three-dimensional cell growth and angiogenesis. Biomaterials 25, 5735, 2004.

49. Sun, H., Mei, L., Song, C., Cui, X., and Wang, P. The in vivo degradation, absorption and excretion of PCL-based implant. Biomaterials 27, 1735, 2006.
50. Oakes, P.W., Patel, D.C., Morin, N.A., Zitterbat, D.P., Fabry, B., Reichner, J.S., and Tang, J.X. Neutrophil morphology and migration is affected by substrate elasticity. Blood 114, 1387, 2009

51. Jannat, R.A., Dembo, M., and Hammer, D.A. Neutrophil adhesion and chemotaxis depend on substrate mechanics. J Phys Condens Matter 22, 194117, 2010

52. Khachighian, L.M. Early growth response-1 in cardiovascular pathology. Circ Res 98, 186, 2006.

53. Eguchi, M., Liu, Y., and Shin, E.J., Sweeney, G. Leptin protects $\mathrm{H} 9 \mathrm{c} 2$ rat cardiomyocytes from $\mathrm{H} 2 \mathrm{O} 2$-induced apoptosis. FEBS J 275, 3136, 2008.

Address correspondence to: Giancarlo Forte, Ph.D

Biomaterials Unit

International Center for Materials Nanoarchitectonics (MANA) National Institute for Materials Science (NIMS)

1-1 Namiki

Tsukuba 305-0044

Japan

E-mail: forte.giancarlo@nims.go.jp

Received: December 13, 2011

Accepted: April 12, 2012

Online Publication Date: June 11, 2012 